\title{
Serendipia: Historias de científicos que revolucionaron la Odontología
}

Patricia Hernández-Rivera

Facultad de Odontología, Universidad de Costa Rica

"A las tablas de La Ley les falta el onceavo mandamiento: Desconfiar de sí mismo y del prójimo”.

Clodomiro Picado Twight (1)

\section{Resumen}

Serendipia, una palabra común en la literatura científica en inglés; pero que luego de casi 300 años de su acuñación no ha sido aceptada por la Real Academia Española. En todo caso, se refiere a los descubrimientos realizados por accidente, casualidad o hechos fortuitos, pero siempre detrás de una mente acuciosa, capaz de comprender, explicar y aplicar, eso que algunos llaman accidentes afortunados, que incluyen desde la ley de la gravedad, la invención de la máquina de vapor y muchos otros inventos, incluyendo descubrimientos de uso cotidiano en la odontología. En esta última rama de las ciencias biológicas, se recopila información referente al estetoscopio, la anestesia, los rayos $\mathrm{x}$, la penicilina y los implantes dentales, todos producto de la serendipia.

Palabras clave: serendipia, estetoscopio, anestesia, rayos $\mathrm{x}$, penicilina, implantes dentales.

\section{ABSTRACT \\ Serendipity: stories of scientists who revolutionized dentistry \\ Serendipity is an usual word in the English scientific literature; but after almost 300 years the}

word still is not accepted by the Real Academia Española. However, it means the discovery by accident, chance or fortuity but always behind a diligent mind, capable of comprehend, explain and apply those fortuity accidents, such as the gravity discover, the invention of the vapor machine and others more, including some inventions of daily use in dentistry. In this branch of biological science, we collect information about the stethoscope, anesthesia, x-rays, penicillin and dental implants all of them have occurred by serendipity.

Key words: serendipity, stethoscope, anesthesia, $\mathrm{x}$ rays, penicillin, dental implants.

\section{INTRODUCCIÓN}

A diario empleamos gran cantidad de instrumentos, materiales, máquinas y artilugios tecnológicos que facilitan nuestra vida diaria e inclusive los consideramos como elementos imprescindibles de nuestra cultura, sin cuestionarnos su origen ni su desarrollo, pues simplemente forman parte del quehacer cotidiano. Sin embargo, es importante señalar que algunas de esas grandes invenciones, e incluso leyes de la física, fueron el producto de accidentes o hallazgos fortuitos, que pudieron acaecerle a muchas personas; pero, la diferencia radica en cuanto ocurrieron a alguien con una mente abierta a nuevas interpretaciones,

Autor para correspondencia: Patricia Hernández-Rivera, Facultad de Odontología, Universidad de Costa Rica E-mail: patricia.hernandezrivera@ ucr.ac.cr

Recibido: el 10 de septiembre de 2015 Aceptado para publicación: el 23 de noviembre de 2015

Este documento está disponible en http://www.revbiomed.uady.mx/pdf/rb162715.pdf

Vol. 27, No. 1, enero-abril de 2016 


\section{Hernández-Rivera}

impregnada de una chispa de creatividad y presta al análisis lógico; es entonces, cuando se interpretaron adecuadamente y se convirtieron en descubrimientos fundamentales; lo cual puede cobijarse bajo el término "Serendipia".

Como bien señaló el ilustre pensador mexicano, Ruy Pérez Tamayo, hace más de 35 años, la palabra serendipia no aparece en el Diccionario de la Real Academia y continúa así, aún en su XXIII edición, de 2014; a pesar de que dicha palabra fue acuñada hace casi 300 años. Tal como relata el Dr. Perez Tamayo (1980), el término se remonta a un personaje interesante, el conde de Oxford, Horace Walpole (1717-1797), uno de los iniciadores de la novela gótica, cuya obra incluye más de 1800 cartas, que han servido para ilustrar y reconstruir la historia europea del siglo XVIII; este personaje, tenía como pasatiempo, inventar palabras, y serendipia fue una de ellas; su origen se puede rastrear en sus cartas, como la dirigida a su amigo Horace Mann, en la cual le relata que la información que buscaba sobre la familia Capello, la encontró en un talismán y que tal hallazgo lo considera "serendipia". Esta palabra la acuñó a partir del cuento, "Los tres príncipes de Serendip" (Serendip, actual Sri Lanka), en el cual se narran las aventuras de tres príncipes, quienes en el trayecto de un viaje, van realizando descubrimientos, cuyo común denominador, es su sagacidad para interpretar audazmente hechos fortuitos o accidentales, que para otras personas pasarían desapercibidos $(2,3$, 4). Aunque esa definición original corresponde más a las deducciones dignas de los detectives Auguste Dupin o Sherlock Holmes (Edgar Allan Poe y Arthur Conan Doyle, respectivamente) (3), fue el nacimiento de este peculiar concepto, que actualmente es tan común en lengua inglesa, que en Google registra más de 20 millones de entradas y en la literatura científica es más común de lo que la mayoría de los científicos imaginan, como se ilustra en este artículo orientado a la odontología; pero si el lector quisiese adentrarse más en sus orígenes, no hay mejor opción que el texto del
Dr. Ruy Perez Tamayo (1980).

El término serendipia se define como la "capacidad de hacer descubrimientos por accidente y sagacidad" (2) o como "la ocurrencia y el desarrollo de eventos fortuitos en un modo beneficioso" (5), en el campo de las artes se hace alusión a él como "accidentes afortunados". Friedel (3) hace referencia a tres tipos o casos donde la serendipia ha jugado un papel importante en el desarrollo científico: El primer tipo alude a Cristobal Colón, quien buscaba una mejor ruta hacia la India y en realidad arribó a América. En esta modalidad se hace referencia a los hechos cuando una persona busca algo y encuentra otra situación ajena a lo que investigaba. Este primer caso, resulta familiar en las búsquedas en la red, por lo que algunos internautas hacen gala de él; sin embargo, algunos ejemplos lo ilustran bien en el campo de las ciencias, como por ejemplo, el descubrimiento de un efecto desconocido del Minoxidil, el cual en primera instancia era antihipertensivo debido a su efecto vasodilador, pero curiosamente, los pacientes tratados con ese fármaco desarrollaban hipertricosis, por lo que luego se comercializó en forma tópica para el tratamiento de la alopecia androgénica (6). El segundo caso se relaciona con la solución accidental o fortuita de un problema, como le ocurrió a Arquímedes, quien pensaba en cómo medir el volumen de una corona y cuando se introdujo en su tina vio que el agua se desplazaba, lo que le hizo pensar que la cantidad de agua desplazada equivaldría al volumen del objeto sumergido; un ejemplo moderno fue el accidente de dejar inadvertidamente caucho con azufre sobre una cocina caliente, acaecido a un joven de escasos recursos económicos, que buscaba como fabricar caucho sintético, por cierto su apellido es Goodyear (5); otro caso fue el invento del velcro, por George de Menestral, quien le sorprendió ver como las diminutas estructuras semejantes a ganchos en las semillas de una hierba, se adherían perfectamente a la tela de sus pantalones y de esa observación nació un aditamento

\section{Revista Biomédica}




\section{Serendipia y Odontología}

más para la industria textil (4). Finalmente, el tipo Galileano, que se refiere a nuevos hallazgos no previsibles, asociados al empleo de instrumentos o conocimientos previos; en este caso, Galileo se sorprendió al mirar a través de un lente que le reveló un mundo diferente como las irregularidades de la luna y las lunas de Marte, entre otros muchos descubrimientos (3). De manera similar, le ocurrió a Antonie van Leeuwenhoek (1632-1723), un comerciante textil que utilizaba lentes para observar la calidad de las telas, pero se apasionó en construir lentes tan potentes que logró desarrollar el primer microscopio de la historia; pero su afición se incrementó aún más cuando pudo observar unos "animalículos", que vivían en las gotas de agua lluvia e, inclusive, en su propio biofilm dental, como lo publicó en varias cartas a la Real Sociedad de Londres $(4,7)$.

Aunque el concepto hace referencia a la existencia de la suerte, accidente o como se diría coloquialmente "chiripa", en realidad involucra una variable aún más importante, la sagacidad; pues solamente una mente abierta, astuta, con alta capacidad investigativa, deductiva y creativa tiene la capacidad de percibir que ese hecho fortuito, error o situación no esperada, se convierta en un descubrimiento relevante. No obstante, a pesar de que esos hallazgos por serendipia solo suceden en un selecto grupo con altas capacidades cognitivas, algunos se avergüenzan de relatar la historia real de su hallazgo, pues éste se desprestigiaría por ser una simple "chiripa" $(3,4,8,9)$. Sin embargo, como menciona Pérez Tamayo, desde la época de Adán y Eva, cuántas personas vieron caer manzanas de los árboles y solo a Newton se le ocurrió la ley de la gravedad (2), la diferencia radica en dejar pasar ese accidente o interpretarlo de manera científica.

El campo de la Odontología, tampoco escapa a la serendipia, por lo que a continuación se hará una breve reseña de algunos descubrimientos que ocurrieron de esta forma con el objetivo de dar a conocer la historia de esos hallazgos bajo la perspectiva de la serendipia, pues son elementos básicos en el armamentum de la profesión y por lo general se desconoce esa versión de los hechos.

\section{El estetoscopio, un invento impulsado por el} pudor. En la actualidad es sencillo pensar en las múltiples metodologías utilizadas para realizar un diagnóstico, pues existe una pléyade de instrumentos, pruebas de laboratorio sofisticadas y exámenes de gabinete que permiten diferenciar las diversas patologías, lograr un diagnóstico, y con ello un plan de tratamiento. No obstante, se ha olvidado el origen del estetoscopio, un dispositivo utilizado diariamente, y que a pesar de su simpleza requiere de un adiestramiento acústico que brinda información fundamental. Su inventor fue René Théophile Hyacinthe Laënnec, nacido en 1781 que a la edad de cinco años quedó huéfano de madre en tanto, su padre, era un abogado irresponsable que pronto quedó en bancarrota (10). El joven René pasó al cuidado de su tío Guillaume, un galeno que se desempeñaba como decano de la Facultad de Medicina en Nantes, quien le sedujo para que estudiara medicina, contra la oposición paterna $(10,11)$. No obstante, Laënnec fue un estudiante destacado por su inteligencia, aunque esa característica hizo que sus colegas sintieran celos profesionales por las observaciones atinadas que realizaba, de las cuales hizo algunas publicaciones (11); también combinaba sus estudios con su pasión por la interpretación musical con flauta $(11,12)$.

Finalmente, su brillante carrera la desempeñaría como médico en el Hospital Necker en París, donde inventaría el estetoscopio, aunque sobre esta historia hay varias versiones (11). Para iniciar el relato es importante recordar que en esa época no se habían descubierto los rayos $\mathrm{x}$, por lo que los diagnósticos se realizaban solamente con el examen físico y auscultaban a los pacientes colocando un pañuelo de seda donde el médico apoyaba la oreja para escuchar los ruidos 


\section{Hernández-Rivera}

cardiacos o pulmonares, pero esta técnica tenía el inconveniente que las mujeres la rechazaban debido a que se sentían avergonzadas (13).

Las biografías sobre Laënnec, relatan que durante el otoño de 1816 , tenía que examinar a una paciente joven y gordita que tenía síntomas de enfermedad cardiaca, entonces, al verse en aprietos debido a que debía colocar su oreja sobre el torax de la paciente, y pensó que además, de hacerla pasar un mal rato tampoco sería capaz de escuchar apropiadamente los ruidos debido a la grasa corporal. Por lo tanto, se le ocurrió realizar con un grupo de hojas de papel un rollo, el cual colocó en la zona precordial y en el otro extremo su oreja y su sorpresa fue que escuchó perfectamente los sonidos cardiacos, inclusive mejor que cuando colocaba directamente su oreja sobre la piel del paciente (10-16). Otra versión relata que Laënnec no quería tener un contacto tan cercano con sus pacientes, por el temor de contraer tuberculosis, pero ya el estaba contagiado de esa enfermedad antes de inventar el estetoscopio, por lo que ésta no sería su preocupación (12).

Ahora bien, ¿cómo se le ocurrió a Laënnec hacer el rollo de hojas? Se dice que, mientras hacía una caminata por los jardines del Louvre, vió a unos niños que estaban jugando con unas tablas de madera, en un extremo un niño tocaba suavemente la tabla con un clavo y al otro lado los niños colocaban sus orejas para escuchar aquellos sonidos; lo cual llamó su atención (10, 12,16). Otra versión relata que, al ser Laënnec un flautista experimentado, conocía los conceptos de transmisión del sonido $(11,13)$. No obstante, lo fundamental fue que sus conocimientos anteriores y su preocupación para resolver el problema se conjugaron para el desarrollo del estetoscopio.

René Théophile Hyacinthe Laënnec, continuó rediseñando su invento hasta que desarrolló un tubo de madera, pues sabía que materiales con densidad media funcionarían mejor (12); éste era un cilindro de 12 pulgadas por

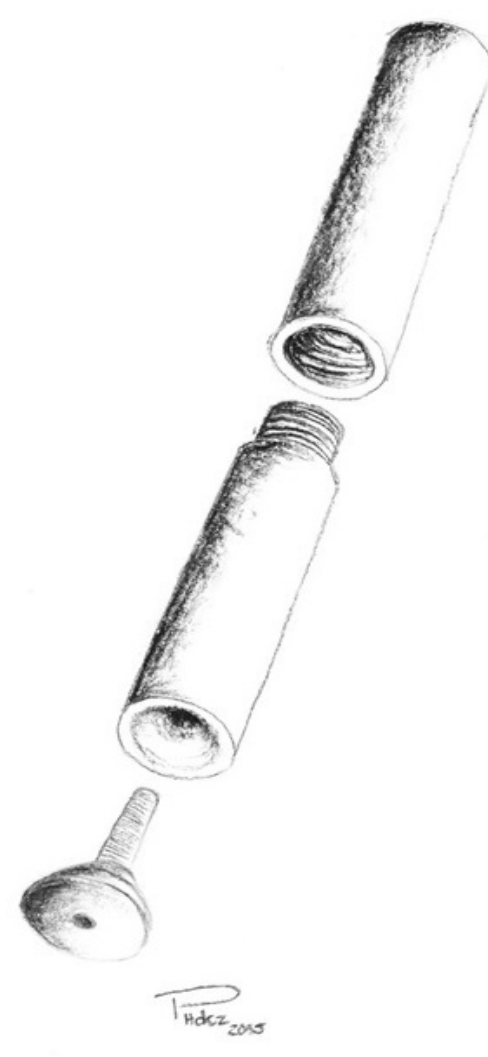

Figura 1. Dibujo del estetoscopio inventado por René Théophile Hyacinthe Laënnec, adaptado de Geddes, 2005 (15)

1,5 pulgadas de diámetro con un agujero central, hecho en dos piezas que se atornillaban entre si y en un extremo también atornillaba una pieza con forma de embudo (Figura 1), ese instrumento se encuentra en el museo de Anestesiología Wood Library Museum, ubicado en el noroeste de Chicago (10, 14-16). Aunque le parecía ilógico ponerle un nombre a un instrumento tan simple, concluyó que el término sería estetoscopio, proveniente de dos palabras griegas stethos que significa pecho y skopein que significa observar y denominó auscultación al estudio médico que se realizaba con éste $(10,12)$.

Su afición no solo fue el desarrollo de ese instrumento, sino que gracias a sus conocimientos en música y la agudeza de su oído pudo realizar investigaciones, donde correlacionaba los sonidos que escuchaba en sus pacientes con sus estudios

\section{Revista Biomédica}




\section{Serendipia y Odontología}

en las autopsias que realizaba $(10,11,14)$; esos hallazgos los publicó en un libro que en sus primeras ediciones, por un monto adicional de 3 francos, se incluía un estetoscopio (11).

Sin embargo, el gremio médico estaba escéptico con el nuevo dispositivo, pues no entendían como era posible que se escuchara mejor que directamente y algunos no deseaban aprender una nueva metodología $(14,15)$. Con el tiempo, los médicos fueron aprendiendo e introdujeron la técnica en su examen físico, hasta llegar al punto que los pacientes pensaban que los médicos que utilizaban ese innovador instrumento estaban más actualizados (15). Quizás esto permite entender la razón por la cual la mayoría de los médicos lo llevaban a diario colgando en su cuello. Al transcurrir el tiempo, su modelo se ha transformado considerablemente, pues en la actualidad es bilateral y flexible $(14,15)$.

Laënnec, es considerado el inventor del estetoscopio y el padre de la medicina torácica, pues enseñó a sus colegas lo que ocurría dentro de esta $(11,14)$ e, irónicamente, murió a la edad de 45 años debido a la tuberculosis que padecía (11).

La anestesia, del circo al consultorio dental. Sin lugar a dudas, la anestesia revolucionó la práctica odontológica y la médica, pues permitió que se pudieran realizar una serie de procedimientos, que, sin la abolición del dolor, eran impensables $\mathrm{y}$, por supuesto, ha ayudado a disminuir el estigma negativo que envuelve ambas profesiones.

Fue Horace Wells, quien de manera similar a Arquímedes resolvió su preocupación. Este personaje nació en enero de 1815, proveniente de una familia de aristócratas, pero se desempeñó como dentista en Connecticut, tras haber aprendido el oficio en Boston; recordemos que la primera Escuela Dental en Estados Unidos abrió sus puertas en 1840, por lo que previo a esa fecha era un quehacer que otros dentistas enseñaban a sus aprendices $(17,18)$. Wells tuvo una práctica privada floreciente y una inteligencia admirable, pues inventó sus propios instrumentos, escribió sobre temas innovadores para ese tiempo, como por ejemplo, medidas preventivas contra la caries; asimismo, enseñó su oficio a varios aprendices que también fueron dentistas destacados (18). Sin embargo, a Wells le atormentaba la incapacidad por suprimir el dolor y esa angustia revoloteaba en su mente (18).

En 1844, asistió con su esposa a un espectáculo circense, en el cual, Gardner Quincy Colton, quien había sido estudiante de medicina, realizaba exhibiciones con el gas óxido nitroso, que causaba un efecto hilarante (18-22). Uno de los voluntarios, Samuel Cooley, que inhaló el gas de la risa, experimentó tal excitación que tropezó con una de las bancas de madera y se hirió seriamente su pierna. Wells se sorprendió al ver que el individuo, no demostraba signos de dolor e, inclusive, no se había percatado de la lesión, por lo que enseguida le preguntó si había sentido dolor y a su respuesta negativa Wells se impresionó aún más (18-20,23). Debido a esto, pensó que probablemente el gas inhalado inhibía de alguna manera misteriosa el dolor, por lo que le solicitó a Colton el gas y decidió probar en si mismo el efecto; para ello, convenció a su colega John Riggs para que le extrajera un tercer molar que le estaba doliendo (17,19-21). Y sorpresa, había descubierto la anestesia.

El hallazgo fue tan increíble, que empezó a utilizarlo en sus pacientes y, tras comprobar el éxito, decidió que sería importante divulgar su hallazgo pues los pacientes tenían el derecho de recibir tratamientos indoloros. Entusiasmado, se contactó con William Morton, un dentista que había sido aprendiz y socio suyo, quién en ese momento se encontraba estudiando medicina; por lo que aprovechó su vínculo académico y lo convenció de organizar una demostración sobre los efectos anestésicos del óxido nitroso $(17,19,20,22)$. Finalmente, la actividad se realizó en el Hospital General de Massachusetts, 


\section{Hernández-Rivera}

donde asistieron los estudiantes de medicina del cirujano John Collins Warren; allí, un voluntario se ofreció para que le extrajeran un diente pero, lamentablemente, en esa época se desconocía sobre la fisiología, la dosificación y los efectos del gas y, cuando Wells extrajo el diente, el paciente se exaltó y gritó, por lo que esa reacción fue percibida por el público como una farsa. Wells fue ridiculizado y catalogado como impostor, lo que lo hizo sentir sumamente avergonzado (1720,22,24).

No obstante, en 1846 viajó a Europa para divulgar su descubrimiento y promover su autoría, pues en esa época el viejo continente era la capital del conocimiento en medicina; también, lo publicó con las pruebas que había realizado en 12-15 pacientes, donde el efecto anestésico había sido exitoso $(18-20,25)$.

Wells continúo probando en si mismo con otros gases, lo que lamentablemente lo volvió adicto al cloroformo. Una noche de 1848, estando drogado le arrojó ácido sulfúrico a unas prostitutas, por lo que fue encarcelado en la prisión de "The New York Halls of Justice and House of Detention", conocida como "The Tombs" $(17,19,20)$. Estando recluido, bajo los efectos del cloroformo se cortó la arteria femoral y falleció desangrado, sin percatarse que unas semanas después sería reconocido como miembro honorable de la Sociedad Médica Parisina y reconocido como el descubridor de la anestesia $(17,18,20,22)$. Posteriormente, la Asociación Americana Dental y la Asociación Americana Médica, también lo declararían como el descubridor de la anestesia (18). A pesar de su trágica muerte, se debe rescatar su espíritu humanista y su preocupación por aliviar el dolor ajeno, además de reconocerlo como un gran científico y quizás, lo más importante, es resaltar el deseo de compartir su conocimiento para que este fuese aplicado en pos de una mejor atención médica (20).

Rayos X y la Roentgenografía. El descubrimiento de los rayos X se fecha el 8 de noviembre de 1895 por Wilhem Conrad Röntgen, nacido el 27 de marzo de 1845 en el seno de una familia con altos ingresos, pues su padre era comerciante textil (2629). Durante su adolescencia fue un estudiante con calificaciones promedio, que causaba constantemente disturbios en las clases y por ello, fue expulsado de la Escuela técnica en Utrecht, tras negarse a develar el nombre del compañero que realizó una caricatura de la profesora; quien asumió que Wilhem era el responsable $(28,29)$. Ese castigo tuvo repercusiones negativas, pues se le dificultó el ingreso a la universidad; no obstante, logró ingresar al politécnico en Zürich a la carrera de ingeniería mecánica de la cual se graduó $(27,28,29)$.

Durante su educación universitaria, el profesor August Kundt se percató del potencial intelectual de Wilhem, por lo que lo recomendó para que trabajara como su profesor asociado, en la Universidad de Würzburg, en Bavaria, donde se desempeñó como un investigador sobresaliente e inclusive fue director del Instituto de Física de Würzburg $(27,28)$.

Su mente inquieta y curiosa lo llevó a investigar los efectos del tubo de rayos catódicos, para ello, hizo varios ensayos hasta que, finalmente, decidió cubrirlo con aluminio y colocarlo en una caja de cartón opaca; su sorpresa fue que observó una fluorescencia en una pantalla de cianoplatino de bario que tenía cerca (26, 29,30). Extrañado, por desconocer el origen de esos rayos, empezó a hacer múltiples pruebas y percibió que atravesaban diferentes tipos de materiales, exceptuando el metal pues, cuando utilizó un libro que tenía una llave que había dejado olvidada, pudo observar dicha imagen (26, 28,29). Sin embargo, uno de sus experimentos claves fue cuando observó la silueta de su mano con la imagen de sus huesos cuando sostenía un trozo de plomo; percatándose que esos rayos desconocidos, por lo cual les denominó "x", tenían una aplicación médica. En este ejemplo de serendipia, Wilhem empleó un tubo de rayos

\section{Revista Biomédica}




\section{Serendipia y Odontología}

catódicos, un instrumento inventado por Crookes pero, el descubrimiento obedeció a su curiosidad, que le llevó a ahondar en el hecho casual de percatarse de que esos misteriosos rayos eran capaces de atravesar diversos materiales $(26,29)$.

El 22 de diciembre de 1895, con 20 minutos de exposición realizó la primera fotografía de una imagen de rayos $\mathrm{x}$, se trataba de la mano de su esposa, en la que se observa la anatomía ósea y su anillo de bodas. Esta es la imagen de rayos x más famosa del mundo (27, 28).

Röntgen logró plasmar la futura utilización de los rayos $\mathrm{x}$ en varias publicaciones científicas y en una conferencia ante la Sociedad Médico Física, donde se encontraba el anatomista August Köller, por lo que su descubrimiento causó gran admiración y aceptación, logrando que se difundiera rápidamente $(26,29,30)$.

Desgraciadamente, en esa época había gran desconocimiento sobre los efectos perjudiciales, había escasa tecnología en la fabricación de películas y tampoco se conocía la dosificación de la radiación, pues era común exponer hasta 80 minutos a un paciente para obtener una imagen, lo que causó gran cantidad de reacciones por sobrerradiación (26). Sin embargo, aunque sin percatarse que los rayos causaban efectos adversos Wilhem, realizó los experimentos en una caja de zinc con una placa de plomo, por lo que se protegió inadvertidamente $(26,28)$.

En 1901 recibió el primer Premio Nobel en Física, a pesar de las críticas por los inventores de los diferentes modelos de tubos de rayos catódicos. Sin embargo, la diferencia radicó en que posiblemente ellos habían visto la fluorescencia, pero no tuvieron la suspicacia de Röntgen, para realizar el descubrimiento que cambiaría por completo el diagnóstico médico y crearía una nueva rama de estudio de la medicina (26,30). Wilhem Conrad Röntgen trabajó hasta 1920 y falleció tres años después de un carcinoma intestinal (28).
Penicilina, del olvido a la creación de un antibiótico. El descubrimiento de la penicilina es uno de los ejemplos más conocidos de la serendipia; se trató del primer antibiótico, con el cual se abrirían las puertas de la antibioticoterapia, lo que revolucionó el curso de las patologías infecciosas, elevó la esperanza de vida y fue el punto de partida para la búsqueda de otros antibióticos.

El hallazgo fue realizado por el médico inglés, Alexander Fleming (1881-1955), quien durante la Primera Guerra Mundial fue reclutado por Almroth Wright para que trabajara en un laboratorio en Bologna, donde investigaban alternativas para tratar las heridas infectadas y la creación de vacunas (31). Es importante acotar en este contexto, que antes de la era de los antibióticos, la mayor causa de mortalidad en los conflictos armados se debía a las heridas infectadas; pues el tratamiento consistía en aplicación de antisépticos como el cresol, aunque Fleming y sus colegas médicos probaban la aplicación de drenajes y una solución salina hipertónica (31). Al finalizar la guerra continuó su trabajo en el Hospital de Saint Mary, en Inglaterra, donde se reconoció su experiencia en el manejo de heridas infectadas; por lo que se convirtió en el Director Asistente del Departamento de Inoculación y Director del Departamento de Bacteriología Sistémica (31). En ese laboratorio, por serendipia, un día que trabajaba estando resfriado, descubrió que sus lágrimas y sus secreciones nasales, que habían contaminado sus placas de cultivos bacterianos, eran capaces de lisar algunas bacterias, por lo cual llamó "lisozima" a esa misteriosa sustancia, que tenía poca relevancia en el campo de la medicina, pues no afectaba los Streptococcus ni Staphylococcus, los principales agentes contra los que luchaba en las heridas dérmicas $(31,32)$.

En 1926, el Consejo de Investigación Médica decidió realizar un libro con toda la información disponible sobre bacteriología, 


\section{Hernández-Rivera}

por lo que le solicitaron a Fleming el capítulo de Staphylococcus (33). Por tanto, Fleming se dispuso a leer la información disponible sobre el tema y encontró una investigación en la que describían colonias de Staphylococcus con una variante de color, lo cual llamó poderosamente su atención y se dispuso a replicar el experimento, lo cual generó que su laboratorio se invadiera de gran cantidad de placas de cultivo con esa bacteria $(33,34)$. En 1928, su desorden y su olvido se confabularían positivamente pues, tras reintegrarse a sus labores luego de un periodo de vacaciones, observó que algunas de sus placas se habían contaminado con un moho de color verdoso, pero le llamó la atención que alrededor de estos había un halo libre de crecimiento bacteriano (31-33,35). Debido a que ya se había enfrentado a una situación similar con las lisozimas, se interesó en esa situación fortuita y determinó que el moho era un Penicillium, por lo que denominó Penicilina a aquella sustancia desconocida que había lisado las bacterias (3133).

Debido al potencial médico de aquella sustancia, publicó en 1929 un artículo científico donde describía la posibilidad terapéutica de la penicilina, en infecciones causadas por bacterias sensibles a ésta, como Staphylococcus aureus, Streptococcus, Haemophilus, Pneumococcus y Meningococcus, a pesar de que esa sustancia era muy inestable y requería de alguna metodología costosa para aislarla $(31,33,35)$. Sin embargo, su descubrimiento quedaría en el olvido, hasta que nuevamente un conflicto bélico movería la investigación tendiente a salvar soldados heridos, esta vez, la Fundación Rockefeller, a mediados de la década de 1930 financió la investigación a Howard Florey y Ernest Chain, quienes encontraron el artículo de Fleming sobre la penicilina (33). Luego de tediosos trabajos de laboratorio lograron aislar $100 \mathrm{mg}$ de penicilina, que probaron en ratones inoculados experimentalmente con Staphylococcus y obtuvieron resultados positivos que publicaron en 1940 en la revista Lancet $(33,35)$. Además, recibieron el apoyo de Norman Heatley, quien elaboró el equipo necesario para producir cantidades suficientes de la nueva droga y un sistema de dosificación que se mantiene en la actualidad (33).

En 1945, de manera conjunta recibieron el Premio Nobel en medicina Alexander Fleming, Howard Florey y Ernest Chain, por el descubrimiento de la Penicilina (35). Durante la ceremonia, Fleming expuso sus sospechas respecto a la posibilidad de la resistencia bacteriana a la nueva droga, cuando no se utilizaba una dosis suficiente para convertirse en bactericida (35). Algunos, critican que Fleming no debió recibir el premio, pues solamente hizo una observación sobre un error que cometió, pues no pudo aislar la sustancia; pero cuántos bacteriólogos previamente habrían descartado las placas contaminadas, sin percatarse que más allá de su descuido había una sustancia que revolucionaría el campo de la medicina (32). Por otro lado, Florey y Chain iniciaron sus investigaciones tras leer la información descrita por Fleming, por lo que el premio fue justo en recompensar a estos tres grandes científicos (34, 36). Sin embargo, previamente a los estudios de Fleming, el científico costarricense Clodomiro Picado Twight (1887-1944) había trabajado arduamente desde 1923, buscando ese mismo efecto antibiótico y publicó una serie de artículos científicos en 1927, los cuales desafortunadamente pasaron al olvido, tal vez por haberlos publicado en francés ante la Sociedad de Biología de París $(1,37)$.

Implantes dentales, de la microscopia vital a la restauración dental. Los implantes dentales también fueron descubiertos por serendipia, y aunque requirió de años de investigación para poder utilizarse en humanos, su aplicación ha revolucionado la restauración dental, pues le ha dado una segunda oportunidad a aquellas personas que han perdido sus piezas dentales.

Per-Ingvar Brånemark nació el 3 mayo

\section{Revista Biomédica}




\section{Serendipia y Odontología}

de 1929 en Suecia, se describía como un amante de la naturaleza debido a sus raíces campestres; cuando entró a la universidad tuvo la oportunidad de estudiar medicina o ingeniería, se decidió por la primera, en la cual también realizó un doctorado en la Universidad de Lund $(38,39)$. Sin embargo, al final su carrera profesional sería la bioingeniería, por medio de la cual innovaría el campo de la medicina y la odontología.

En 1952, investigaba en la Universidad de Gothemburg, el sanado y la reparación ósea en vivo, por medio de una metodología llamada "microscopia vital", en la cual se analizaba la médula ósea por transiluminación (40-43). Para ello, había rediseñado unos dispositivos para ser insertados en el fémur de conejos; a diferencia del que empleaban en Inglaterra, que aplicaban en las orejas y eran hechos en tantalio, metal que no encontró en Suecia y que sustituyó por titanio (41-43). Después de varios meses de estudio, decidió remover las cámaras para reutilizarlas y su sorpresa fue que estaban totalmente adheridas al hueso e inclusive el punto de fractura era en hueso y no en la unión entre el metal y la superficie ósea; sin embargo, en principio le restó importancia a esa anécdota y procedió a adaptar nuevamente los aparatos para introducirlos en brazos de voluntarios, para analizar la microcirculación en humanos (40-43). Nuevamente se impresionó al observar que tanto los tejidos duros como los blandos reaccionaron adecuadamente, sin signos de inflamación, al titanio; por lo tanto redirigió su investigación, pues se percató que ese hallazgo tendría aplicaciones médicas (41-43).

Posteriormente, gracias al apoyo financiero del gobierno sueco y al trabajo colaborativo de su grupo de trabajo, realizó investigaciones en perros Beagle, lo que le permitió analizar el proceso biomolecular y los procedimientos necesarios para lograr una unión sólida entre los implantes de titanio y el hueso, concepto que denominó como "osteointegración" y que estudió por más de 10 años $(42,43)$. Motivado por los resultados positivos en los estudios realizados en canes, en 1965 se aventuró a trabajar con humanos y aplicó por primera vez cuatro implantes a un hombre que tenía una deformidad importante en la mandíbula y ausencia de algunos órganos dentales $(41,42)$.

No obstante, a pesar de los resultados exitosos su descubrimiento fue muy criticado, pues los científicos pensaban que era imposible que el hueso se adhiriera fuertemente a un objeto extraño; asimismo, los dentistas estaban escépticos ante los tratamientos de Brånemark, pues él era un médico que estaba irrumpiendo la profesión odontológica (44). Por lo tanto, el Consejo Sueco de Salud le solicitó a tres odontólogos que analizaran los pacientes que habían recibido implantes dentales (44). También en esa época entrenó a un grupo de odontólogos canadienses; quienes en 1982 organizaron un congreso donde Brånemark discutió el concepto de osteointegración y dio a conocer casos clínicos a profesores de las diferentes facultades de odontología en Estados Unidos de América $(41,44)$.

Finalmente, gracias a su mente abierta, su ingenio y la capacidad para desarrollar sus intuiciones, brindó una opción terapéutica conservadora con alta predictibilidad, así como un protocolo quirúrgico y los procedimientos clínicos para lograr que el tratamiento fuera exitoso $(45,46)$. Brånemark, logró extraer de una anécdota no esperada, un tratamiento que revolucionó la rama de la prostodoncia, permitiendo que pacientes con edentulismo parcial o total, acceder a tratamientos que les permiten gozar de una mejor calidad de vida.

\section{CONCLUSIÓN}

Quizás existan otros casos de descubrimientos por serendipia que se desconocen, pues algunos investigadores temen que sus hallazgos sean menospreciados, por ser una simple casualidad. Por ello, es importante comprender a cabalidad el concepto, pues es muy probable que a muchas personas les ocurran situaciones no esperadas o erróneas; pero solo un grupo selecto tiene la capacidad de observar, intuir e investigar que ese hecho tendría una aplicación 


\section{Hernández-Rivera}

relevante. Por lo tanto, cuando pensemos que la suerte no está de nuestro lado, por cometer alguna equivocación o por presentarse una situación fortuita, deberíamos detenernos y analizar, pues quizás podríamos ser los autores de un gran descubrimiento, cuya expresión final sería la emulación de Arquímedes, cuando gritó ¡Eureka!

\section{REFERENCIAS}

1. Picado Twight C. Obras completas Clodomiro Picado. Vol. 6, Intervenciones del Dr. C. Picado T. en la prensa. Costa Rica: Editorial Tecnológica de Costa Rica; 1988.

2. Pérez Tamayo R. Serendipia ensayos sobre ciencia, medicina y otros sueños. Mexico: Siglo veintiuno editores; 1980.

3. Friedel R. Serendipity is no accident. Kenton Rev. 2001; 23 (2): 36-47.

4. Hoffmann R. Serendipity, the Grace of Discovery. Innovation. 2005; 5 (2): 68- 69.

5. Coppo JA. Serendipia. Rev Vet. 2012; 23 (1):71-76.

6. Zins G. The History of the Development of Minoxidil. ClinDermatol. 1988 Oct-Dec; 6(4): 132-147.

7. Mikx F. A. van Leeuwenhoek's microscopes: Upside down? The Lancet. 1983 June 18; 1 (8338): 13871388.

8. Díaz CL. Serendipity Citations in the Biomedical Sciences. Creativity Res J. 1997; 10 (1): 91-95.

9. Baumeister A, Hawking MF, López Muñoz F.Toward Standardized Usage of the Word Serendipity in the Historiography of Psychopharmacology. Journal of the History of Neuroscience. 2010; 19: 253-270.

10. Billimoria AR. Rene Laennec. JAPI. 2012 Jul; 60: 62.

11. Seaton A. Alas, poor Laënnec! Q J Med. 2011; 104:275-277.

12. Cheng TO. How Laënnec invented the stethoscope. Int J Cardiol. 2007; 118: 281-285.

13. Aronson SM. A heart-beat is amplified and then resonates in history. Med Health R I. 2012 Jun; 95(6): 171.

14. Wallen RD. Acoustic stethoscopes.Biomed Instrum Technol. 2006 Sep-Oct; 40(5):367-70.

15. Geddes LA. Birth of the stethoscope.IEEE Eng Med Biol Mag. 2005 Jan-Feb; 24(1):84-6.

16. Roguin A. Rene Theophile Hyacinthe Laënnec (17811826): The Man Behind the Stethoscope. Clinical Medicine \& Research. 2006; 4 (3): 230-235.

17. Ellis H. Horace Wells: pioneer of nitrous oxide anaesthesia. Br J Hosp Med (Lond). 2015 Jan; 76(1):56.

18. Jacobsohn PH. Horace Wells: Discoverer of Anesthesia. AnesthProg. 1995; 42: 73-75.
19. Haridas RP. Horace wells' demonstration of nitrous oxide in Boston. Anesthesiology. 2013 Nov; 119(5):1014-22.

20. Finder SG. Lessons from history: Horace Wells and the moral features of clinical contexts. AnesthProg. 1995; 42(1):1-6.

21. Wright AJ. Davy Comes to America: Woodhouse, Barton, and the Nitrous Oxide Crossing. J Clin Anesth. 1995 Jun; 7:347-355.

22. Le Vasseur R, Desai SP. Ebenezer Hopkins Frost (1824-1866): William T.G. Morton's first identified patient and why he was invited to the Ether demonstration of October 16, 1846. Anesthesiology. 2012 Aug; 117(2):238-42.

23. Malamed SF. Local anesthetics: Dentistry's most important drugs. JADA. 1994 Dec; 125: 1571-1576.

24. Menczer LF, Jacobsohn PH. Dr. Horace Wells: The Discoverer of General Anesthesia. J Oral Maxillofac Surg. 1992; 50: 506-509.

25. López-Valverde A, Montero J, Abaladejo A, Gómez de Diego R. The Discovery of Surgical Anesthesia: Discrepancies Regarding Its Authorship. J Dent Res. 2011; 90(1):31-34.

26. Frankel RI. Centennial of Rontgen's Discovery of X-rays. West J Med. 1996; 164: 497-501.

27. Haas L. Wilhelm Conrad Von Röntgen (1845-1923). Journal of Neurology, Neurosurgery, and Psychiatry. 2001; 70(1):126.

28. Daniel TM. Wilhelm Conrad Röntgen and the advent of thoracic radiology. Int J Tuberc Lung Dis. 2006; 10(11):1212-1214.

29. Wong VS, Tan SY. Wilhelm Conrad Röntgen (18451923): a light in the dark. Singapore Med J. 2009 Sep; 50(9):851-2.

30. Widder $\mathbf{J}$. The origins of radiotherapy: discovery of biological effects of X-rays by Freund in 1897, Kienböck's crucial experiments in 1900, and still it is the dose. RadiotherOncol. 2014 Jul; 112(1):150-2.

31. Bentley R. Different roads to discovery; Prontosil (hence sulfa drugs) and penicillin (hence betalactams). J IndMicrobiolBiotechnol. 2009 Jun; 36(6):775-86.

32. Hernández- Chavarría F, Rivera P. Serendipia e Investigación en Microbiología. Rev. Col. de MQC de Costa Rica. 2001; 8(1): 6-9.

33. Kingston W. Irish contributions to the origins of antibiotics. Ir J Med Sci. 2008; 177:87-92.

34. Bentley R. The development of penicillin: genesis of a famous antibiotic. Perspect Biol Med. 2005 summer; 48 (3): 444-452.

35. Wennergren G, Lagercrantz H. "One sometimes finds what one is not looking for" (Sir Alexander Fleming): the most important medical discovery of the 20th century. ActaPædiatrica/ActaPædiatrica. 


\section{Serendipia y Odontología}

2007; 96:141-144.

36. Geddes A. 80th Anniversary of the discovery of penicillin: An appreciation of Sir Alexander Fleming. Int J Antimicrob Agents. 2008 Nov; 32(5):373.

37. Gamboa E. Con el Dr. Don Clodomiro Picado y a propósito de la penicilina. Revista de la Asociación Nacional de Educadores. 1943; 1(3): 3-5.

38. Brånemark PI. On looking back with Per-Ingvar Brånemark. Interview.Int J Prosthodont. 2004 JulAug; 17(4):395-6.

39. Zarb G, Lekholm U, Albrektsson T. In memoriam: Per-Ingvar Brånemark. Int J Prosthodont. 2015 JanFeb; 28(1):8.

40. Abraham CM. A Brief Historical Perspective on Dental Implants, their surface coatings and treatments. Open Den J.2014; 8(Suppl 1-M2): 50-55.
41. Sullivan RM. Implant dentistry and the concept of osseointegration: a historical perspective. J Calif Dent Assoc. 2001 Nov; 29(11):737-45.

42. Ring ME. A thousand years of dental implants: a definitive history--part 2. Compend Contin Educ Dent. 1995 Nov; 16(11):1132-1146.

43. Brånemark PI. Osseointegration and its experimental background. J ProsthetDent. 1983 Sep; 50(3):399-410.

44. Albrektsson T, Wennerberg A.The impact of oral implants - past and future, 1966-2042. J Can Dent Assoc. 2005 May; 71(5):327.

45. Esposito M. Editorial: a tribute to Professor PerIngvar Brånemark. Eur J Oral Implantol. 2015 Spring; 8(1):3-4.

46. Zarb G. In honor of an outstanding role model.Int J Prosthodont. 2004 Jul-Aug; 17(4):394. 